\title{
Diagnosis of Eosinophilic Esophagitis in Children: A Serbian Single-Center Experience from 2010 to 2017
}

\author{
Nina Ristic ${ }^{a}$ Radmila Jankovic ${ }^{b}$ Natasa Dragutinovic ${ }^{a}$ \\ Marina Atanaskovic-Markovic c, d Milica Radusinovic ${ }^{a}$ Marija Stevic d, e \\ Milos Ristic ${ }^{f}$ Maja Ristic ${ }^{g}$ Tamara Milovanovic ${ }^{d, h}$
}

${ }^{a}$ Department of Gastroenterology, Hepatology and GI Endoscopy, University Children's Hospital, Belgrade, Serbia; ${ }^{b}$ Institute of Pathology, Faculty of Medicine, University of Belgrade, Belgrade, Serbia; 'Department of Pulmonology and Allergology, University Children's Hospital, Belgrade, Serbia; ' Faculty of Medicine, University of Belgrade, Belgrade, Serbia; ${ }^{e}$ Department of Anesthesia, University Children's Hospital, Belgrade, Serbia; ${ }^{\mathrm{f}}$ Emergency Center, Clinical Center of Serbia, Belgrade, Serbia; ${ }^{9}$ Department of Nutrition and Food Safety Control, Institute for Public Health of Belgrade, Belgrade, Serbia; ${ }^{\mathrm{h}}$ Clinic for Gastroenterology and Hepatology, Clinical Center of Serbia, Belgrade, Serbia

\section{Significance of the Study}

- The esophageal biopsy rate should be increased in children with nonspecific and reflux symptoms. In children with suspected or confirmed eosinophilic esophagitis, the number of biopsy samples should be increased for better detection of subepithelial fibrosis. Eosinophilic esophagitis should be suspected and repeat endoscopy may be recommended after successful treatment of infectious esophagitis in immunocompetent children.

\section{Keywords}

Eosinophilic esophagitis · Children · Subepithelial fibrosis
3.77 years) with a male predominance (74\%). The median incidence rate was estimated to be 0.85 per 100,000 children per year with the highest rate estimated at 3.17 per 100,000 children in 2017. Dysphagia (71.4\%) and food impaction (40\%) were dominant symptoms. Inflammatory endoscopic changes were found in $74.3 \%$ and fibrostenotic changes in $62.9 \%$ of the children. The esophageal biopsy rate was low (6.8\%), especially in children with reflux and nonspecific symptoms. Subepithelial fibrosis was found in only $20 \%$ of the patients. Since 2016, the number of biopsy samples has increased, but the sampling rate of lamina propria is still low $(<50 \%)$. The correlation between the number of biopsies

\begin{tabular}{|c|c|c|}
\hline KARGER & $\begin{array}{l}\text { (c) } 2019 \text { The Author(s) } \\
\text { Published by S. Karger AG, Basel }\end{array}$ & $\begin{array}{l}\text { Karger } \\
\text { Open access }\end{array}$ \\
\hline $\begin{array}{l}\text { E-Mail karger@karger.com } \\
\text { www.karger.com/mpp }\end{array}$ & $\begin{array}{l}\text { This is an Open Access article licensed ur } \\
\text { Attribution-NonCommercial-4.0 Intern } \\
\text { (http://www.karger.com/Services/Open } \\
\text { the online version of the article only. Usa } \\
\text { mercial purposes requires written permi }\end{array}$ & $\begin{array}{l}\text { er the Creative Commons } \\
\text { onal License (CC BY-NC) } \\
\text { cessLicense), applicable to } \\
\text { and distribution for com- } \\
\text { ion. }\end{array}$ \\
\hline
\end{tabular}

Nina Ristic

Department of Gastroenterology, Hepatology and GI Endoscopy

University Children's Hospital

Tirsova 10, RS-11000 Belgrade (Serbia)

E-Mail nina.ristic13@gmail.com 
and lamina propria acquisition was strong $\left(r_{\mathrm{s}}=0.773, p<\right.$ 0.05). In 2 immunocompetent adolescents, EoE was diagnosed after successful treatment of infectious esophagitis. Conclusions: An increase in the incidence of EoE in Serbian children is evident. The biopsy rate in children with nonspecific and reflux symptoms should be increased, as well as the number of biopsy samples for the detection of subepithelial fibrosis. In immunocompetent children with infectious esophagitis, EoE should be suspected and endoscopy may be recommended after successful treatment of infection.

(C) 2019 The Author(s)

Published by S. Karger AG, Basel

\section{Introduction}

Eosinophilic esophagitis (EoE) is a chronic inflammatory disorder of the esophagus, first described in 1977, but was defined as a distinct entity only in 1993. Currently, EoE is the second most common cause of chronic esophagitis after gastroesophageal reflux disease (GERD), as well as the main cause of dysphagia and food impaction in children. EoE is defined as a chronic, local immunemediated esophageal disease, clinically characterized by symptoms related to esophageal dysfunction and histologically by eosinophil-predominant inflammation [1]. Due to the patchy distribution of inflammatory changes [2], at least 6 biopsies should be taken from different parts of the esophagus [1].

The first guidelines on EoE were published in 2007 [3] assuming that EoE and GERD mutually exclude each other. Moreover, for the purpose of diagnosing EoE it was necessary for the proton pump inhibitor (PPI) trial and/ or $\mathrm{pH}$ monitoring to be negative. However, these recommendations were updated in 2011, when the term "proton pump inhibitor-responsive esophageal eosinophilia" (PPI-REE) was introduced. PPI-REE has been diagnosed in patients with clinical, endoscopic, and histological characteristics of EoE and PPI-induced clinical and histological remission, who are not necessarily diagnosed with GERD [4]. The difference in response to PPI was the key feature in distinguishing PPI-REE from EoE [5-7]. However, studies published after 2011 demonstrated that PPI-REE and EoE do not differ even on the genetic level and that both disorders are distinct from GERD $[4,8]$. The latest guidelines on EoE (2017) emphasized the importance of PPI, particularly as a treatment option for EoE, while the term PPI-REE has been withdrawn [1].

Therefore, the aim of this study was to assess epidemiological, clinical, endoscopic, and pathohistological

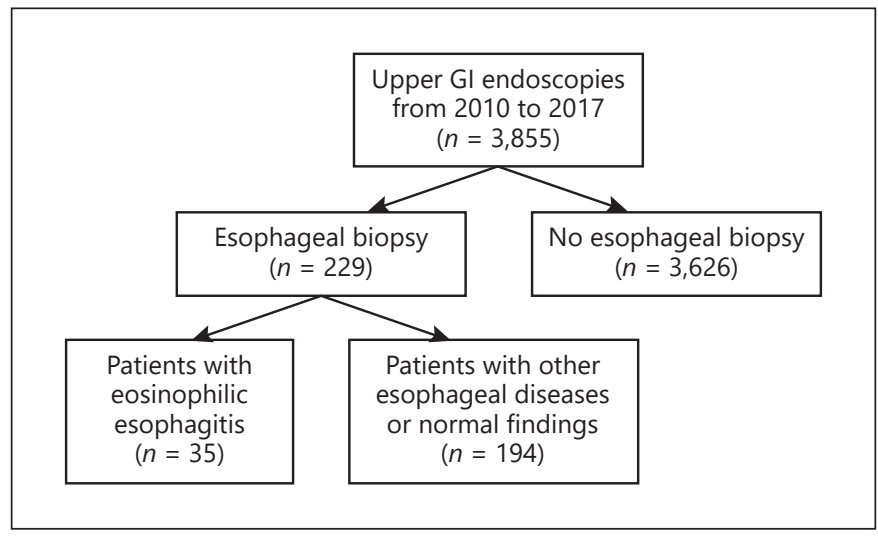

Fig. 1. Study design. GI, gastrointestinal.

characteristics of pediatric EoE according to the current recommendations for the first time in the Serbian population.

\section{Materials and Methods}

Study Design

All children aged 0-18 years with esophageal symptoms undergoing an upper endoscopy between January 2010 and December 2017 at the Department of Gastroenterology, Hepatology and Endoscopy of the University Children's Hospital in Belgrade were retrospectively enrolled in the study.

We included all children who met the histological criteria for EoE ( $\geq 15$ eosinophils per HPF in esophageal mucosa, taken as the peak concentration in the specimens examined) [1]. Children with eosinophilic gastroenteritis (i.e., eosinophilic infiltration of different parts of the gastrointestinal tract), infectious esophagitis, achalasia, hypereosinophilic syndrome, hypersensitivity reactions to drugs, vasculitis, and connective tissue disorders were excluded from the study. The study design is presented in Figure 1. Esophageal biopsy rates (\% of patients in whom esophageal biopsies were performed), number of esophageal biopsy samples per exam, as well as the percentage of biopsy samples with lamina propria for each year are presented in Table 1.

For each child, clinical presentation, endoscopic and histological findings, skin and blood allergy tests, as well as personal history of allergy and infectious esophagitis were analyzed. Additionally, the majority of children underwent multichannel intraluminal impedance (MII)-pH monitoring. We compared differences in clinical, endoscopic, and pathohistological presentation between children under the age of 10 years and adolescents.

Finally, all children who met the inclusion criteria and whose parent/caregiver gave written consent were included in the study. The study was approved by the Ethics Committee of University Children's Hospital Belgrade.

\section{Esophagogastroduodenoscopy}

The following endoscopic findings, associated with EoE, were retrospectively analyzed from endoscopy reports comprising mu- 
Table 1. Esophageal biopsy rate, number of biopsy samples, and lamina propria acquisition in patients who underwent upper gastrointestinal endoscopy

\begin{tabular}{lclc}
\hline Year & $\begin{array}{l}\text { Esophageal biopsy } \\
\text { rate, \% }(n / \text { total } n)\end{array}$ & $\begin{array}{l}\text { Esophageal biopsy } \\
\text { samples, mean } \pm \text { SD }\end{array}$ & $\begin{array}{c}\text { Biopsy samples with } \\
\text { lamina propria, \% }(n / \text { total } n)\end{array}$ \\
\hline 2010 & $2.4(8 / 330)$ & $1.2 \pm 0.4$ & $10(1 / 10)$ \\
2011 & $2.7(10 / 375)$ & $1.2 \pm 0.4$ & $0(0 / 12)$ \\
2012 & $9(38 / 421)$ & $1.4 \pm 0.4$ & $9.6(5 / 52)$ \\
2013 & $8.4(39 / 461)$ & $1.2 \pm 0,3$ & $8.3(4 / 48)$ \\
2014 & $2.5(14 / 564)$ & $1.1 \pm 0.3$ & $0(0 / 16)$ \\
2015 & $4.9(29 / 586)$ & $1.2 \pm 0.3$ & $0(0 / 34)$ \\
2016 & $8.9(52 / 580)$ & $2.6 \pm 0.7$ & $7.3(10 / 137)$ \\
2017 & $13.2(71 / 538)$ & $3.2 \pm 0.8$ & $10(25 / 230)$ \\
Overall & $6.8(261 / 3,855)$ & $2.1 \pm 0.6$ & $8.3(45 / 539)$ \\
\hline
\end{tabular}

Fig. 2. Number of newly diagnosed patients with eosinophilic esophagitis from 2010 to 2017.

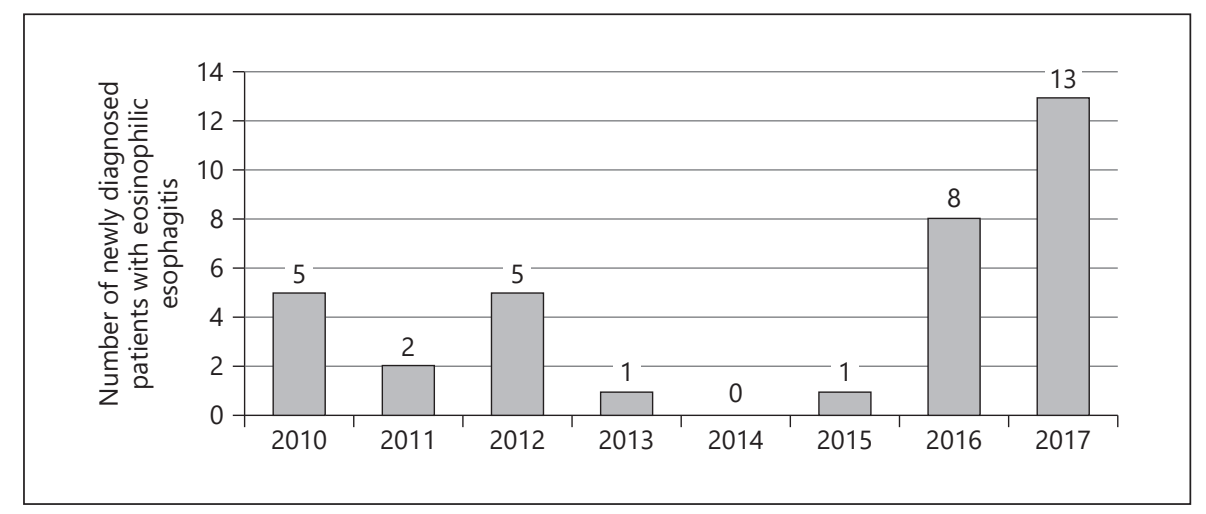

cosal edema, longitudinal furrowing, rings, white plaques, strictures, and narrow caliber esophagus.

\section{Histopathological Analysis}

For the pathohistological assessment, hematoxylin-eosin staining has been used. The reevaluation of old samples was performed in order to assess the following features: peak eosinophil count, eosinophil microabscesses, basal-zone hyperplasia, dilated intercellular spaces, eosinophil surface layering, papillary elongation, and lamina propria fibrosis. Additionally, Masson's trichrome staining was used to further determine the presence of subepithelial fibrosis in some patients.

\section{MII-pH Monitoring}

MII-pH monitoring was performed by a $\mathrm{pH}-\mathrm{MII}$ ambulatory system (Sandhill Scientific, Denver, CO, USA). The catheter was introduced nasally after at least $3 \mathrm{~h}$ of fasting. The minimum required recording time was $20 \mathrm{~h}$. The $\mathrm{pH}-\mathrm{MII}$ recordings were automatically analyzed using the software package (AutoScan/ BioView Analysis, Sandhill Scientific, Highlands Ranch, CO, USA) and reviewed manually.

Statistical Analysis

Normality of data distribution was tested using the coefficient of variation and the Kolmogorov-Smirnov test. Descriptive measures

Eosinophilic Esophagitis in Serbian Children were presented according to the variable characteristics: means and standard deviations for parametric variables, medians and interquartile ranges for nonparametric numeric variables, and percentages for categorical variables. Parametric data were compared using Student's $t$ test. Nonparametric numerical data were compared using the Mann-Whitney U test. Categorical variables were compared using the $\chi^{2}$ test and Fisher's exact probability. Correlation was performed by Spearman correlation. Statistical significance was established at $p<0.05$. SPSS 17.0 (Chicago, IL, USA) was used.

\section{Results}

EoE was diagnosed in 35 children (mean $12.45 \pm 3.77$ years, range 3-18) during the period from January 2010 to December 2017. Out of 35 children, 26 (74.3\%) were boys (mean $13.07 \pm 3.67$ years), while 9 (25.7\%) were girls (mean $10.67 \pm 3.67$ years); however, this difference in age between boys and girls was not statistically significant $(t=1.691, p>0.05)$.

An increase was evident in the number of newly diagnosed patients with EoE in 2016 and 2017 relative to pre- 
Table 2. Clinical presentation and endoscopy findings in different age groups

\begin{tabular}{|c|c|c|c|c|}
\hline & $\begin{array}{l}\text { Overall } \\
(n=35)\end{array}$ & $\begin{array}{l}\text { Children }<10 \text { years } \\
(n=11)\end{array}$ & $\begin{array}{l}\text { Children } \geq 10 \text { years } \\
(n=24)\end{array}$ & $p$ value \\
\hline Gender, boys/girls & $26 / 9$ & $8 / 3$ & $18 / 6$ & 1.000 \\
\hline \multicolumn{5}{|l|}{ Symptoms, $n(\%)$} \\
\hline Dysphagia & $25(71.4)$ & $7(63.6)$ & $18(75)$ & 0.689 \\
\hline Reflux symptoms & $8(22)$ & $2(18.2)$ & $6(25)$ & 1.000 \\
\hline Retrosternal pain & $3(8.6)$ & $1(9.1)$ & $2(8.3)$ & 1.000 \\
\hline Food impaction & $14(40)$ & $4(36.4)$ & $10(41.7)$ & 1.000 \\
\hline \multicolumn{5}{|c|}{ Upper endoscopy findings, $n(\%)$} \\
\hline Longitudinal furrowing & $25(71.4)$ & $9(81.8)$ & $16(66.7)$ & 0.447 \\
\hline White plaques & $11(31.4)$ & $5(45.5)$ & $6(25)$ & 0.263 \\
\hline Ring & $21(60)$ & $5(45.5)$ & $16(66.7)$ & 0.283 \\
\hline Esophageal stricture & $3(8.6)$ & 0 & $3(12.5)$ & 0.536 \\
\hline Erosive esophagitis & $4(11.4)$ & $1(9.1)$ & $3(12.5)$ & 1.000 \\
\hline Inflammatory changes & $26(74.3)$ & $9(81.8)$ & $17(70.8)$ & 0.685 \\
\hline Fibrostenotic changes & $22(48.6)$ & $5(45.5)$ & $17(70.8)$ & 0.258 \\
\hline
\end{tabular}

vious years as shown in Figure 2. The number of newly diagnosed EoE patients per year correlated strongly with the esophageal biopsy rate $\left(r_{\mathrm{s}}=0.743, p<0.05\right)$ and the number of biopsies per exam $\left(r_{\mathrm{s}}=0.952, p<0.001\right)$. In Serbia, about $30 \%$ of children diagnosed with pediatric gastrointestinal diseases are referred to University Children's Hospital. Therefore, the estimated median incidence rate of EoE in Serbian children from 2010-2017 was 0.85 per 100,000 children per year. The highest incidence rates were 3.17 per 100,000 children in 2017 and 1.95 per 100,000 children in 2016 . The estimated prevalence of pediatric EoE in Serbia was 6.83 per 100,000 children. Clinical presentation and endoscopy findings in different age groups are presented in Table 2. In 6 (17.1\%) patients, food impaction was the first symptom. The youngest patient was a 3-year-old girl with reflux symptoms and food refusal. Reflux symptoms were more prevalent in girls (55.6\%) than in boys (11.5\%) (Fisher's test, $p=0.015$ ).

The median time from the occurrence of the first symptoms to diagnosis was $3 \pm 23.5$ months (range $0-120$ ), $3 \pm 23.9$ months (range $0-24$ ) in the younger group and $3.5 \pm 21.5$ months (range $0-120$ ) in the older group. This difference was not statistically significant $(p>0.05)$. The median time from the occurrence of the first symptoms to diagnosis was longer from 2010 to 2015 (4.5 \pm 15.5 months) than from 2016 to 2017 (3.0 \pm 23.9 months), with no significant difference $(p>0.05)$. There were no significant differences in age (Table 2$)$ and gender concerning endoscopic findings $(p>0.05)$. Inflammatory changes (longitudinal furrowing, white plaques) were found in $74.3 \%$ of children, fibrostenotic changes (rings, strictures) in $62.9 \%$ of children, and both in $48.6 \%$ of children. There were no significant differences in sex, age groups, and type of symptoms $(p>0.05)$.

The number of endoscopic signs in each patient was analyzed. In each patient, 4 endoscopic signs were analyzed: longitudinal furrowing, rings, white plaques, and esophageal strictures. Mucosal edema, although often present, was not described in most endoscopic reports and, therefore, was not analyzed. Out of 35 patients, 4 (11.4\%) children had normal endoscopic findings. A single endoscopic sign was found in $9(25.7 \%)$ children, 2 signs in $16(45.7 \%)$ children, and 3 signs in $3(17.1 \%)$ children. Seven $(20 \%)$ children had pathological acid reflux on $\mathrm{pH}-\mathrm{MII}$ monitoring (reflux index $>7 \%$ ), while 4 children had erosive esophagitis.

Histopathological analysis of esophageal mucosa revealed a median peak number of $77.5 \pm 44$ eosinophils per HPF in EoE children (range 13-146). Eosinophilic microabscesses were found in 23 (65.7\%) children. There were no statistically significant differences in sex, age groups, and type of symptoms concerning these parameters $(p>0.05)$. The findings of the patient with marked subepithelial fibrosis in addition to eosinophilic infiltration are shown in Figure 3. Subepithelial fibrosis was found in 7 (20\%) children. Unfortunately, the presence of fibrosis was rarely evaluated until 2016, when it was found to be present in $30 \%$ of patients. Subepithelial tissue was included in $16.5 \%$ of biopsy samples. The rate of acquisition of lamina propria was $31.4 \%$ (47.6\% in $2016-$ 2017 and $7.1 \%$ in $2010-2015$ ), and the detection rate of 

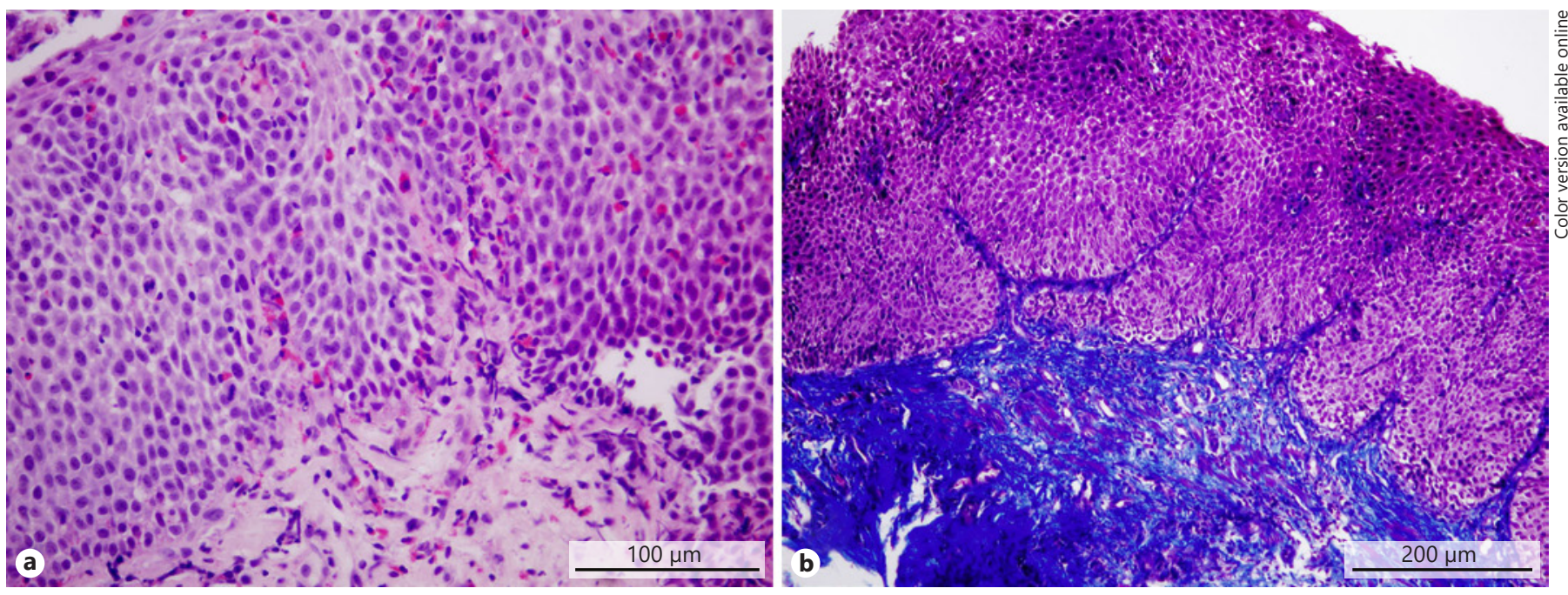

Fig. 3. Pathohistological findings of a patient with fibrostenotic phenotype of eosinophilic esophagitis. a Eosinophilic mucosal infiltration (HE staining). b Subepithelial fibrosis (blue on Masson's trichrome staining).

subepithelial fibrosis was $70 \%$. The number of esophageal biopsies per exam was low in 2010-2015. The mean number of biopsy samples was $5.0 \pm 0.9$ in 2016 and 6.0 \pm 1.0 in 2017. The correlation between the number of biopsies and lamina propria acquisition was strong $\left(r_{\mathrm{s}}=\right.$ $0.773, p<0.05)$. Food and/or respiratory allergies were demonstrated in $14(40 \%)$ children with positive skin prick test and/or specific IgE antibodies. Food allergy was found in $9(26 \%)$ children and respiratory allergy in 5 (14\%) children. The diagnosis of allergic asthma was established in $3(8.6 \%)$ children. Ten out of $14(71.4 \%)$ children were allergic to multiple allergens. IgE-mediated milk allergy was found in $3(8.6 \%)$ children, egg allergy in $4(11.4 \%)$ children, and wheat allergy in $2(5.7 \%)$ children.

EoE was diagnosed in 2 brothers aged 16 and 17.5 years. In 1 sibling, esophageal candidiasis was found during the initial presentation (dysphagia, odynophagia, and epigastric pain). After successful treatment with fluconazole, a diagnosis of EoE was made. In 1 adolescent, herpes simplex virus (HSV) esophagitis was found during primary diagnostic workup. After treatment with acyclovir, additional diagnostic procedures revealed EoE. Both adolescents were immunocompetent.

Eight (22.9\%) children were treated only with six food elimination diet (SFED), whereas 8 (22.9\%) children were treated with PPIs and $4(11.4 \%)$ children only with topical corticosteroids. Fifteen (42.8\%) children were treated with more than 1 therapeutic modality.

Eosinophilic Esophagitis in Serbian Children

\section{Discussion}

The incidence and prevalence of EoE in Serbian children is lower than previously reported in a meta-analysis from 2016 that included 13 population-based studies from North America, Europe, and Australia [9]. In the meta-analysis, the incidence of EoE in children was estimated to be 5.1 (95\% CI 1.5-10.9) per 100,000 children per year, whereas the prevalence was 19.1 (95\% CI 7.9$32.5)$ per 100,000 children. An evident increase in the incidence of pediatric EoE in Serbia in 2016 and 2017 is due to greater attention by physicians, a higher rate of esophageal biopsies, and better pathohistological analysis, as previously reported [10].

In our study, the male predominance was noted to be similar to that reported in the literature [9]. Several studies have shown that presentation of EoE is age dependent. Liacouras et al. [11], as well as Gonsalves [12], reported that the most common symptoms are feeding problems, failure to thrive, and reflux symptoms in infants and young children, vomiting, abdominal pain, and regurgitation in school children, and dysphagia and food impaction in adolescents. In adults, the most common symptoms are dysphagia (70-80\%) and food impaction (33$54 \%)[1,13,14]$. However, our study did not reveal a significant difference between different age groups. The reasons for these differences are a small sample size, a small number of infants and young children diagnosed with EoE, as well as selection bias. The main indications for serial biopsies in children were dysphagia and food

Med Princ Pract 2019;28:449-456 
impaction due to the high degree of suspicion for EoE. On the other hand, serial biopsies have not been routinely done in children with reflux symptoms. Some authors believe that histological analysis is not mandatory in patients with reflux symptoms, while others recommend biopsies in order to exclude other pathologies, such as EoE [15].

The median time from the onset of symptoms to the diagnosis in our study was short, probably due to the fact that mild nonspecific symptoms were not recognized (or reported). On the other hand, the time range was wide (0-120 months). A prospective study in adults demonstrated that in the absence of anti-inflammatory therapy or elimination diet, dysphagia and esophageal eosinophilia persisted with the development of subepithelial fibrosis [16]. The results of several retrospective studies have shown that the greatest risk for esophageal remodeling and stricture formation is diagnostic delay $[5,17]$. Another study revealed that for every 10 years the risk of fibrostenosis was doubled (OR 2.1, 95\% CI 1.7-2.7), while dysphagia increased the risk 7 times (OR 7, 95\% CI 2.618.6) [18]. Warners et al. [19] reported that the main risk factors for stricture formation were diagnostic delay (OR $1.09,95 \%$ CI 1.05-1.13) and male gender (OR 2.69, 95\% CI 1.61-4.50). Early detection of EoE and early initiation of therapy (during the inflammatory stage) are of great importance. Therefore, the biopsy rate in children with nonspecific and reflux symptoms should be increased.

Studies have shown that fibrostenotic changes (rings, strictures, and narrow caliber esophagus) are more frequent in adults, while inflammatory changes (edema, white plaques, and longitudinal furrowing) are more frequent in children [12]. In our study, the prevalence of fibrostenotic changes (62.9\%) was higher than expected. In the study of Warners et al. [19], fibrostenotic changes were found in $39 \%$ of children and in $76 \%$ of adults with EoE. Another meta-analysis showed modest sensitivity as well as modest negative and positive predictive values of endoscopic signs in patients with EoE [20]. However, this study showed greater frequencies of fibrostenotic changes in adults than in children ( 57 vs. $11 \%$ for rings, 25 vs. $11 \%$ for strictures). White plaques and mucosal edema were more common in children than in adults (36 vs. $19 \%$ for white plaques, 58 vs. $18 \%$ for mucosal ede$\mathrm{ma}$ ). In our study, the frequency of rings was higher than previously reported (60 vs. $11 \%$ ), but this did not apply to strictures (6.8 vs. $11 \%)$. Also, the frequency of erosive esophagitis was slightly lower in our patients (11 vs. $17 \%)$, as well as the frequency of normal endoscopic findings (11 vs. $17 \%)$.
In one study, subepithelial fibrosis was found in $12 / 21$ (57\%) children with EoE [21]. Dysphagia and food impaction were present only in patients with fibrosis, while $42 \%$ of patients with fibrosis had dysphagia and $80 \%$ had food impaction. However, the problem is that subepithelial fibrosis in patients with EoE can be detected only if a sufficient amount of lamina propria is obtained. Wang et al. [22] reported that the sample rate of adequate amounts of lamina propria was low in patients with $\mathrm{EoE}(43 \%)$ and controls (31\%) $(p=0.14)$. In this study, $85 \%$ of EoE patients had fibrosis, including children with only inflammatory endoscopic signs. In order to reliably detect subepithelial fibrosis, it was necessary that at least 7 biopsy samples from central and distal parts of the esophagus be taken (detection rate over 95\%) [22]. As far as our study is concerned, until 2016, the number of esophageal biopsies was often inadequate and lamina propria was rarely described due to an insufficient amount of lamina propria. Since 2016, the number of biopsy samples has increased, but the sampling rate of lamina propria is still low, which needs to be analyzed further.

Atopy is present in $50-60 \%$ of patients with newly diagnosed EoE [23, 24], which is slightly above the frequency found in our study (40\%). IgE-mediated food allergy was found in 15-43\% of patients with EoE [23, 24], which is in concordance with our results. Milk, egg, and wheat are the most common triggers of EoE, evidenced by sequential re-introduction after elimination diet and repeated biopsies [25, 26]. In our study, multiple food allergy was found in $70 \%$ of patients, whereas IgE-mediated allergy to milk, egg, and wheat was less frequent than expected. Nevertheless, our results support the hypothesis that IgE-mediated food allergy can be considered as a predictive factor for the development of EoE in children [27].

HSV esophagitis is a severe acute viral esophagitis, which rarely occurs in immunocompetent patients. In our study, HSV esophagitis was diagnosed during the primary diagnostic workup in an immunocompetent adolescent, and subsequent evaluation revealed EoE. Zimmerman et al. [28] reported HSV esophagitis in 5 patients with EoE not previously treated with topical steroids. It is unlikely that these 2 rare diseases occur simultaneously by coincidence, suggesting that EoE may predispose to HSV infection. In a retrospective study from 2018, data on 16 children (11 immunocompetent) with HSV esophagitis diagnosed from 1982 to 2016 were analyzed [29]. EoE was diagnosed in $5(45 \%)$ immunocompetent patients after successful treatment of HSV infection, and 4/5 children had a personal history of atopy. There are no data in the literature on the relationship of esophageal candidiasis 
with EoE in immunocompetent patients not treated with topical steroids. Thus, it could be hypothesized that EoE causes a reduction in local defense leading to subsequent infection, which must be further investigated.

Until 2017, topical steroids or SFED were used as firstline treatments. After new recommendations were published in 2017, PPIs became the first-line therapy. In 2 children with no response to PPIs, SFED has been started with an ongoing evaluation. In almost half of our patients, several modalities of treatment were applied due to the lack of response or a negative impact on the quality of life. However, further prospective investigations of effectiveness are necessary.

\section{Conclusion}

It is necessary to create a register of patients with EoE in Serbia. The esophageal biopsy rate in children with nonspecific and reflux symptoms needs to be increased because the early detection and treatment of EoE are of great importance. In immunocompetent children with infectious esophagitis, EoE should be suspected and repeat endoscopy may be recommended after successful treatment of infection. In order to reliably detect subepithelial fibrosis, an adequate amount of lamina propria is required, which could be achieved by increasing the number of biopsy samples.

\section{Statement of Ethics}

Written consent was obtained from the children's parents/ caregivers for inclusion in the study. The study was approved by the Ethics Committee of University Children's Hospital Belgrade.

\section{Disclosure Statement}

The authors have no conflicts of interest to declare.

\section{References}

1 Lucendo AJ, Molina-Infante J, Arias Á, von Arnim U, Bredenoord AJ, Bussmann C, et al. Guidelines on eosinophilic esophagitis: evidence-based statements and recommendations for diagnosis and management in children and adults. United European Gastroenterol J. 2017 Apr;5(3):335-58.

2 Saffari H, Peterson KA, Fang JC, Teman C, Gleich GJ, Pease LF 3rd. Patchy eosinophil distributions in an esophagectomy specimen from a patient with eosinophilic esophagitis: implications for endoscopic biopsy. J Allergy Clin Immunol. 2012 Sep;130(3):798-800.

3 Furuta GT, Liacouras CA, Collins MH, Gupta SK, Justinich C, Putnam PE, et al.; First International Gastrointestinal Eosinophil Research Symposium (FIGERS) Subcommittees. Eosinophilic esophagitis in children and adults: a systematic review and consensus recommendations for diagnosis and treatment. Gastroenterology. 2007 Oct;133(4):1342-63.

4 Molina-Infante J, Ferrando-Lamana L, Ripoll C, Hernandez-Alonso M, Mateos JM, Fernandez-Bermejo M, et al. Esophageal eosinophilic infiltration responds to proton pump inhibition in most adults. Clin Gastroenterol Hepatol. 2011 Feb;9(2):110-7.

5 Liacouras CA, Furuta GT, Hirano I, Atkins D, Attwood SE, Bonis PA, et al. Eosinophilic esophagitis: updated consensus recommendations for children and adults. J Allergy Clin Immunol. $2011 \mathrm{Jul} ; 128(1): 3-20 . e 6$; quiz 21-2.

Eosinophilic Esophagitis in Serbian Children
6 Dellon ES, Gonsalves N, Hirano I, Furuta GT, Liacouras CA, Katzka DA; American College of Gastroenterology. ACG clinical guideline: evidenced based approach to the diagnosis and management of esophageal eosinophilia and eosinophilic esophagitis (EoE). Am J Gastroenterol. 2013 May; 108(5):679-92; quiz 693.

7 Papadopoulou A, Koletzko S, Heuschkel R, Dias JA, Allen KJ, Murch SH, et al.; ESPGHAN Eosinophilic Esophagitis Working Group and the Gastroenterology Committee. Management guidelines of eosinophilic esophagitis in childhood. J Pediatr Gastroenterol Nutr. 2014 Jan;58(1):107-18.

8 Dellon ES, Speck O, Woodward K, Gebhart $\mathrm{JH}$, Madanick RD, Levinson S, et al. Clinical and endoscopic characteristics do not reliably differentiate PPI-responsive esophageal eosinophilia and eosinophilic esophagitis in patients undergoing upper endoscopy: a prospective cohort study. Am J Gastroenterol. 2013 Dec;108(12):1854-60.

9 Arias Á, Pérez-Martínez I, Tenías JM, Lucendo AJ. Systematic review with meta-analysis: the incidence and prevalence of eosinophilic oesophagitis in children and adults in population-based studies. Aliment Pharmacol Ther. 2016 Jan;43(1):3-15.

10 Syed AA, Andrews CN, Shaffer E, Urbanski SJ, Beck P, Storr M. The rising incidence of eosinophilic oesophagitis is associated with increasing biopsy rates: a population-based study. Aliment Pharmacol Ther. 2012 Nov; 36(10):950-8.
11 Liacouras CA, Spergel J, Gober LM. Eosinophilic esophagitis: clinical presentation in children. Gastroenterol Clin North Am. 2014 Jun;43(2):219-29.

12 Gonsalves N. Distinct features in the clinical presentations of eosinophilic esophagitis in children and adults: is this the same disease? Dig Dis. 2014;32(1-2):89-92.

13 Remedios M, Campbell C, Jones DM, Kerlin P. Eosinophilic esophagitis in adults: clinical, endoscopic, histologic findings, and response to treatment with fluticasone propionate. Gastrointest Endosc. 2006 Jan;63(1):3-12.

14 Croese J, Fairley SK, Masson JW, Chong AK, Whitaker DA, Kanowski PA, et al. Clinical and endoscopic features of eosinophilic esophagitis in adults. Gastrointest Endosc. 2003 Oct;58(4):516-22.

15 Genevay M, Rubbia-Brandt L, Rougemont AL. Do eosinophil numbers differentiate eosinophilic esophagitis from gastroesophageal reflux disease? Arch Pathol Lab Med. 2010 Jun;134(6):815-25.

16 Straumann A, Spichtin HP, Grize L, Bucher KA, Beglinger C, Simon HU. Natural history of primary eosinophilic esophagitis: a followup of 30 adult patients for up to 11.5 years. Gastroenterology. 2003 Dec;125(6):1660-9.

17 Lipka S, Kumar A, Richter JE. Impact of diagnostic delay and other risk factors on eosinophilic esophagitis phenotype and esophageal diameter. J Clin Gastroenterol. 2016 Feb; 50(2):134-40. 
18 Dellon ES, Kim HP, Sperry SL, Rybnicek DA, Woosley JT, Shaheen NJ. A phenotypic analysis shows that eosinophilic esophagitis is a progressive fibrostenotic disease. Gastrointest Endosc. 2014 Apr;79(4):577-85.e4.

19 Warners MJ, Oude Nijhuis RA, de Wijkerslooth LR, Smout AJ, Bredenoord AJ. The natural course of eosinophilic esophagitis and long-term consequences of undiagnosed disease in a large cohort. Am J Gastroenterol. 2018 Jun;113(6):836-44.

20 Kim HP, Vance RB, Shaheen NJ, Dellon ES. The prevalence and diagnostic utility of endoscopic features of eosinophilic esophagitis: a meta-analysis. Clin Gastroenterol Hepatol. 2012 Sep;10(9):988-96.e5.

21 Chehade M, Sampson HA, Morotti RA, Magid MS. Esophageal subepithelial fibrosis in children with eosinophilic esophagitis. J Pediatr Gastroenterol Nutr. 2007 Sep;45(3):31928.
22 Wang J, Park JY, Huang R, Souza RF, Spechler SJ, Cheng E. Obtaining adequate lamina propria for subepithelial fibrosis evaluation in pediatric eosinophilic esophagitis. Gastrointest Endosc. 2018 May;87(5):1207-1214.e3.

23 Prasad GA, Alexander JA, Schleck CD, Zinsmeister AR, Smyrk TC, Elias RM, et al. Epidemiology of eosinophilic esophagitis over three decades in Olmsted County, Minnesota. Clin Gastroenterol Hepatol. 2009 Oct;7(10):105561.

24 Almansa C, Krishna M, Buchner AM, Ghabril MS, Talley N, DeVault KR, et al. Seasonal distribution in newly diagnosed cases of eosinophilic esophagitis in adults. Am J Gastroenterol. 2009 Apr; 104(4):828-33.

25 Lucendo AJ, Arias Á, González-Cervera J, Yagüe-Compadre JL, Guagnozzi D, Angueira $\mathrm{T}$, et al. Empiric 6-food elimination diet induced and maintained prolonged remission in patients with adult eosinophilic esophagitis: a prospective study on the food cause of the disease. J Allergy Clin Immunol. 2013 Mar;131(3):797-804.
26 Molina-Infante J, Arias A, Barrio J, Rodríguez-Sánchez J, Sanchez-Cazalilla M, Lucendo AJ. Four-food group elimination diet for adult eosinophilic esophagitis: A prospective multicenter study. J Allergy Clin Immunol. 2014 Nov;134(5):1093-9.e1.

27 Dellon ES, Gibbs WB, Fritchie KJ, Rubinas TC, Wilson LA, Woosley JT, et al. Clinical, endoscopic, and histologic findings distinguish eosinophilic esophagitis from gastroesophageal reflux disease. Clin Gastroenterol Hepatol. 2009 Dec;7(12):1305-13; quiz 1261.

28 Zimmermann D, Criblez DH, Dellon ES, Bussmann C, Pfeifer D, Froh M, et al. Acute herpes simplex viral esophagitis occurring in 5 immunocompetent individuals with eosinophilic esophagitis. ACG Case Rep J. 2016 Apr;3(3):165-8.

29 Fritz J, Lerner D, Suchi M. Herpes simplex virus esophagitis in immunocompetent children: A harbinger of eosinophilic esophagitis? J Pediatr Gastroenterol Nutr. 2018 Apr;66(4): 609-13. 